\title{
Antidepressant Effect of Combined Ketamine and Electroconvulsive Therapy on Patients With Major Depressive Disorder: A Randomized Trial
}

\author{
Narges Shams Alizadeh, Azad Maroufi, ${ }^{2,}$ Karim Nasseri, ${ }^{3}$ Seyed Hosein Sadeghi Najafabadi, \\ Ali Mousavi Taghiabad, ${ }^{2}$ Fardin Gharibi, ${ }^{4}$ and Gholam Reza Esfandiari ${ }^{2}$ \\ ${ }_{1}^{1}$ Kurdistan Research Center for Social Determinants of Health, Department of Psychiatry, Qods Hospital, Kurdistan University of Medical Sciences, Sanandaj, IR Iran \\ ${ }_{3}^{2}$ Department of Psychiatry, Qods Hospital, Kurdistan University of Medical Sciences, Sanandaj, IR Iran \\ ${ }^{3}$ Departments of Anesthesia and Intensive Care, Kurdistan University of Medical Sciences, Sanandaj, IR Iran \\ ${ }^{4}$ Deputyship of Research, Kurdistan University of Medical Sciences, Sanandaj, IR Iran \\ ${ }^{*}$ Corresponding author: Azad Maroufi, Department of Psychiatry, Qods Hospital, Kurdistan University of Medical Sciences, Sanandaj, IR Iran. Tel: +98-9183711193, \\ E-mail: maroufimd@gmail.com
}

Received: February 19, 2015; Revised: March 7, 2015; Accepted: July 14, 2015

\begin{abstract}
Background: One of the shortcomings of the available treatments for major depressive disorder(MDD) is the time delay between starting the treatment and achieving an antidepressant response.

Objectives:Weaimed to determine the effect of Ketamine as a synergistic antidepressant and anestheticagent on MDD in electroconvulsive therapy (ECT).

Patients and Methods: Twenty-two patients with MDD received Ketamine and Propofol as anesthetic agents compared with 20 patients as the control group who received Propofol in a double-blind randomized clinical trial. The Hamilton rating scale for depression was used to determine the changes in symptoms severity during ECT and a 2-week follow-up.

Results: Both groups showed a reduction in depression severity, but there was no significant difference between the groups in the recovery process $(\mathrm{P}=0.92)$. However, the cognitive performance recovery time in the Ketamine group was lower than that in the control $\operatorname{group}(\mathrm{P}=0.042)$.

Conclusions: This study could not show the effect of Ketamine on depression recovery in a 2-week follow-up period. Nevertheless, Ketamine may provide a better cognitive performance in patients under ECT.
\end{abstract}

Keywords: Antidepressants; Electroconvulsive Therapy; Ketamine

\section{Background}

One of the shortcomings of the available treatments for major depressive disorder (MDD) is the time delay between commencing the treatment and achieving an antidepressant response. Most of the approved drugs for such treatment need at least 2 to 4 weeks for the onset of their effects, and sometimes the peak of drug efficacy is achieved after 6 - 8 weeks (1).

The fast effectiveness and the short period between the onset of action and the relief of symptoms are the major advantages of electroconvulsive therapy (ECT) compared with common antidepressant drugs; however, similar to drugs, the time delay between the start of ECT and its effect is still a weak point of this treatment modality $(2,3)$. Despite the relative superiority of ECT to drugs in the treatment of MDD, the patients' suffering caused by the symptoms and the possibility of harmful behaviors in the period between the start of treatment and the response to it still remains one of the major challenges in the treatment of depression.
Ketamine is a non-competitive inhibitor of the N-methyl-D-aspartic acid (NMDA) receptors. It is sometimes used for induction of anesthesia in ECT because it neither raises the convulsive threshold nor impairs cognition (4). Furthermore, there are some evidences showing the elevated mood in patients receiving Ketamine (5-7). Hence it seems that the induction of anesthesia by Ketamine, which has mood enhancing effects, during ECT, may expedite the process of MDD recovery.

Recent studies suggest the probability of the synergic effects of ECT and Ketamine in accelerating the recovery of patients, but controversial results make performing more research in this field mandatory (8). Some reports show that Ketamine during ECT can have neuroprotective effects and reduce its cognitive side effects to some extent $(7,9)$, while other studies report effects to the contrary. Additionally, according to the results of some other investigations, Ketamine itself may cause cognitive impairments (10). It, therefore, seems that more studies are

Copyright (C) 2015, Mazandaran University of Medical Sciences. This is an open-access article distributed under the terms of the Creative Commons Attribution-NonCommercial 4.0 International License (http://creativecommons.org/licenses/by-nc/4.0/) which permits copy and redistribute the material just in noncommercial usages, provided the original work is properly cited. 
needed to illuminate the effect of Ketamine on patients cognitive conditions after ECT.

\section{Objectives}

The present report evaluates the role of Ketamine in accelerating antidepressant effects and its cognitive effect after ECT.

\section{Patients and Methods}

This double-blind randomized clinical trial study recruited MDD patients who received ECT in Qods Hospital, Sanandaj, West of Iran, between July 2010 and June 2012. The inclusion criteria were comprised of age between 18 and 65 years, normal IQ, suffering from MDD according to the diagnostic and statistical manual of mental disorders, 4th edition, text revision (DSM-IVTR) criteria, and having a score of 20 or higher in the Hamilton rating scale for depression (HRSD). The HRSD scores, vital signs, and duration of reorientation were collected by an author who was blind to group assignment. The patients were also blind to the received medication and only the anesthesiologist responsible for the induction of anesthesia knew which patient received which drug.

The exclusion criteria consisted of substance or drug dependence for up to at least 3 months before the study, any contraindication for receiving ECT, cognitive impairment, epilepsy, receiving ECT in the previous 3 months, and anesthesiology class $>$ II according to the American society of anesthesiologists (ASA) physical status classification system. All the included patients provided a written informed consent.

This study was approved by the ethics committee of Kurdistan university of medical sciences and was registered in the Iranian registry of clinical trials (IRCT. ir\#IRCT138811022935N2). As the study was done under close observation in the hospital, no changes were made in the type and doses of the already prescribed drugs. The number of ECT sessions was determined by the physician.

Considering $\alpha=0.05, \beta=0.1, \delta=3.5$, and $d=2.5$, the sample size was calculated as 22 patients in each intervention and control group. The patients were allocated randomly using the block randomization method. The patients in the intervention group received Ketamine with Propofol and those in the control group received normal saline and Propofol.

The HRSD scores were obtained one day before ECT onset, the day after the third session, the day after the last session, and finally 2 weeks after the last session. The minimum score needed to participate in the study was considered 20 and response to treatment was considered as at least a 50\% reduction in the score after the last session.

At time 0 , the intervention group received $0.3 \mathrm{mg} /$ $\mathrm{kg}$ of Ketamine Hydrochloride (manufactured by RO-
TEXMEDICA, Germany) intravenously (IV) which was diluted with $5 \mathrm{~mL}$ of saline; and in the control group, Ketamine was replaced with $5 \mathrm{~mL}$ of Normal Saline. After 30 seconds, both groups received $0.5 \mathrm{mg}$ of Atropine IV. Thirty seconds later, after the loss of eyelid reflex, anesthesia was induced with $1 \mathrm{mg} / \mathrm{kg}$ of Propofol 1\% IV (manufactured by Fresenius Kabi, Austria GmbH). Muscle relaxation was achieved by the administration of $0.5 \mathrm{mg} / \mathrm{kg}$ of Succinylcholine IV. Before Succinylcholine administration, a manometer cuff was fastened to one of the legs and blown up to $30 \mathrm{~mL}$ higher than systolic pressure and was retained until the end of seizure. Propofol complementary doses were administered if needed. Then, in all the patients, lung ventilation with $100 \%$ oxygen was performed by mask. The anesthesiologist was the only person aware of the administered drugs.

After complete relaxation, electric stimulation was performed using an ECT apparatus (IEC 601-1 Type BF Class 1, IRAN) with bifrontotemporal electrode placement. For the first session, the patients received $30 \%$ to $50 \%$ of maximum output stimulus. The blood pressure and heart rate of the patients were also evaluated 5 minutes after the motor seizures were ended.

To assess the patients' cognitive performance recovery time, 10 questions relating to orientation were asked at 5-minute intervals, after terminating the motor seizures (Box 1). The minimum cognitive performance recovery time was considered when the patient was able to answer all the 10 questions correctly. Similar assessments have been performed to measure the patients' cognitive performance recovery time in previous studies $(7,11)$.

Box 1. Assessment of the Patients' Cognitive Performance Recovery Time

\begin{tabular}{lc}
\hline $\mathbf{c}$ & $\begin{array}{c}\text { Questions for Evaluating the Patients' } \\
\text { Cognitive Performance Recovery Time }\end{array}$ \\
\hline $\mathbf{1}$ & What is your name? \\
$\mathbf{3}$ & How old are you? \\
$\mathbf{4}$ & Where do you work? \\
$\mathbf{5}$ & Where do you live? \\
\hline $\mathbf{6}$ & What day is it? \\
\hline $\mathbf{7}$ & What season is it? \\
\hline $\mathbf{8}$ & Where are we (building, city, and county)? \\
\hline $\mathbf{9}$ & What is the name of your doctor? \\
\hline
\end{tabular}


The data were entered into STATA(v.12) software. Repeated measurement was used to compare the trend of the HRSD, blood pressure, heart rate, seizure duration, and cognitive performance recovery time at different time points. The within-subject contrasts test was employed to assess the interaction effects between group and time. The sphericity assumption was assessed with the Mauchly test. The average of the P values after adjusting the degree of freedom through the Greenhouse-Geisser and Huynh-Feldt was reported for some of the variables for which sphericity assumption was rejected.

\section{Results}

In the control group, one patient was excluded because of consent withdrawal for ECT and one more patient was excluded because of early discharge from the hospital. Finally, of the 42 patients whose data were analyzed at the end of the study, 22 patients were in the intervention group (27.3\% men and $72.7 \%$ women) and 20 patients (35\% men and $65 \%$ women) were in the control group (Figure 1). The two groups had no significant difference in sex distribution $(\mathrm{P}=$ $\left.0.74, \chi^{2}=0.29, \mathrm{df}=1\right)$, education level $\left(\mathrm{P}=0.72, \chi^{2}=1.5, \mathrm{df}=3\right)$, and mean age $(\mathrm{P}=0.82, \mathrm{t}=0.23, \mathrm{df}=40)($ Table 1$)$.

There was no significant difference in the motor seizure duration between the two groups $(\mathrm{P}=0.395, \mathrm{df}=5, \mathrm{~F}=$ 1.04) (Table 2).

The mean cognitive performance recovery time in the intervention group was lower than control group $(\mathrm{P}=0.042$, $\mathrm{df}=5, \mathrm{~F}=2.36$ ) (Figure 2 and Table 2 ).

A comparison of the HRSD scores showed similar changes between the groups. There were no significant differences between the groups in terms of the rate and speed of the recovery process $(\mathrm{P}=0.82, \mathrm{df}=3, \mathrm{~F}=0.31$ ) (Figure 3 , Table 2 ). The results of this study did not show any significant difference in cardiac side effects between the patients in both groups before and after ECT (Table 2). Other plausible side effects of Ketamine such as postictal agitation, hallucination, or derealization were not seen in the participants of either group.

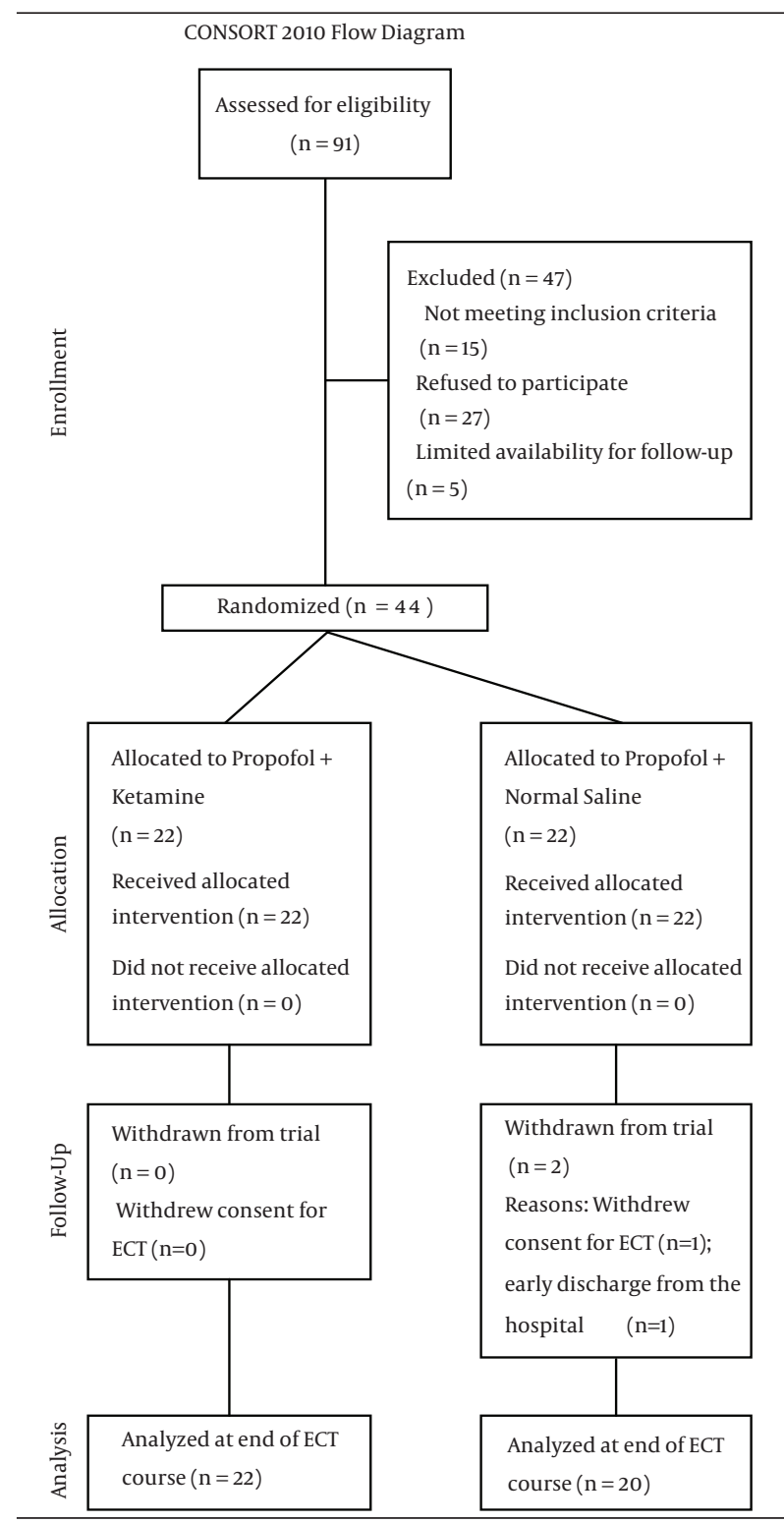

Figure 1. Consort Diagram, Showing the Recruitment and Progress of the Trial Participants

Table 1. Demographic Characteristics of the Patients in the Ketamine and Control Groups a

\begin{tabular}{|c|c|c|c|}
\hline Variable & Ketamine Group & Control Group & PValue \\
\hline \multicolumn{4}{|l|}{ Gender } \\
\hline Male & $6(27.3)$ & $7(35)$ & $0.74^{b}$ \\
\hline Female & $16(72.7)$ & $13(65)$ & \\
\hline \multicolumn{4}{|l|}{ Education } \\
\hline Illiterate & $4(18.2)$ & $4(20)$ & $0.72^{b}$ \\
\hline Primary school & $2(9.1)$ & $4(20)$ & \\
\hline High school & $9(40.9)$ & $8(40)$ & \\
\hline Academic & $7(31.8)$ & $4(20)$ & \\
\hline Age & $34.27 \pm 10.66$ & $35.1 \pm 12.44$ & $0.82^{\mathrm{C}}$ \\
\hline
\end{tabular}


Shams Alizadeh $N$ et al.

Table 2. Comparison of the Intervention Outcomes and Side Effects Between the Ketamine and Control Groups ${ }^{\text {a,b }}$

\begin{tabular}{|c|c|c|c|c|c|c|c|c|c|}
\hline Groups & T1 & T2 & T3 & T4 & T5 & T6 & d.f & $\mathbf{F}$ & P Value \\
\hline \multicolumn{10}{|c|}{ Motor Seizure Duration, $s c$} \\
\hline Ketamine & $32.2 \pm 17.4$ & $35.5 \pm 12.2$ & $30.5 \pm 13.8$ & $30.1 \pm 12.4$ & $33.1 \pm 12.4$ & $26.2 \pm 5.85$ & 5 & 1.04 & 0.395 \\
\hline Control & $27.3 \pm 12.5$ & $32.3 \pm 12.2$ & $31.6 \pm 11.07$ & $29.5 \pm 10.6$ & $26.4 \pm 8.2$ & $25.5 \pm 5.2$ & & & \\
\hline \multicolumn{10}{|c|}{$\begin{array}{l}\text { Mean Cognitive } \\
\text { Performance Recovery } \\
\text { Time, minc }\end{array}$} \\
\hline Ketamine & $20.7 \pm 6.7$ & $19.6 \pm 7.5$ & $17.6 \pm 5.2$ & $15.8 \pm 4.7$ & $15.5 \pm 5.5$ & $17.4 \pm 5.3$ & 5 & 2.36 & 0.042 \\
\hline Control & $23.3 \pm 8.7$ & $22.3 \pm 7.8$ & $24.2 \pm 9.7$ & $22.3 \pm 6.5$ & $22 \pm 8.5$ & $20.8 \pm 7.3$ & & & \\
\hline
\end{tabular}

Systolic Blood Pressure ${ }^{c}$

\begin{tabular}{|c|c|c|c|c|c|c|c|c|c|}
\hline Ketamine & $-7.63 \pm 18.56$ & $-8.31 \pm 16.72$ & $-10.13 \pm 26.63$ & $-10.75 \pm 14.4$ & $0 \pm 31.23$ & $-13 \pm 11.58$ & 5 & 0.4 & 0.848 \\
\hline Control & $-4.4 \pm 11.18$ & $-11.85 \pm 13.21$ & $-11.75 \pm 14.54$ & $-15.07 \pm 13.14$ & $-3.16 \pm 18.02$ & $-10.08 \pm 10.84$ & & & \\
\hline
\end{tabular}

\section{Diastolic Blood Pressure $^{c}$}

\begin{tabular}{|c|c|c|c|c|c|c|c|c|c|}
\hline Ketamine & $-6.3 \pm 16.5$ & $-7.5 \pm 11.9$ & $-13.27 \pm 14.6$ & $-9.7 \pm 10.2$ & $-3.81 \pm 12.5$ & $-12.4 \pm 9.9$ & 5 & 0.84 & 0.523 \\
\hline Control group & $-5.9 \pm 9.6$ & $-10.6 \pm 11.05$ & $-13.1 \pm 11.7$ & $-11.4 \pm 10.2$ & $2.58 \pm 17.02$ & -10.10 .8 & & & \\
\hline \multicolumn{10}{|c|}{ Mean HRSD Scores d } \\
\hline Ketamine & $35.4 \pm 6.7$ & $21.86 \pm 6.28$ & $16.27 \pm 6.4$ & $14.18 \pm 11.83$ & & & 0.82 & 0.31 & 3 \\
\hline Control & $36.44 \pm 7.17$ & $22.83 \pm 10.48$ & $14.77 \pm 6.82$ & $14.33 \pm 9.46$ & & & & & \\
\hline
\end{tabular}

\footnotetext{
a Abbreviation: HRSD, Hamilton rating scale for depression.

$\mathrm{b}$ Data are presented as mean \pm standard deviation.

C T: ECT session.

$\mathrm{d}$ T: time of follow-up.
}

Figure 2. Comparison of the Mean Cognitive Performance Recovery Time (Minute) Between the Ketamine and Control Groups

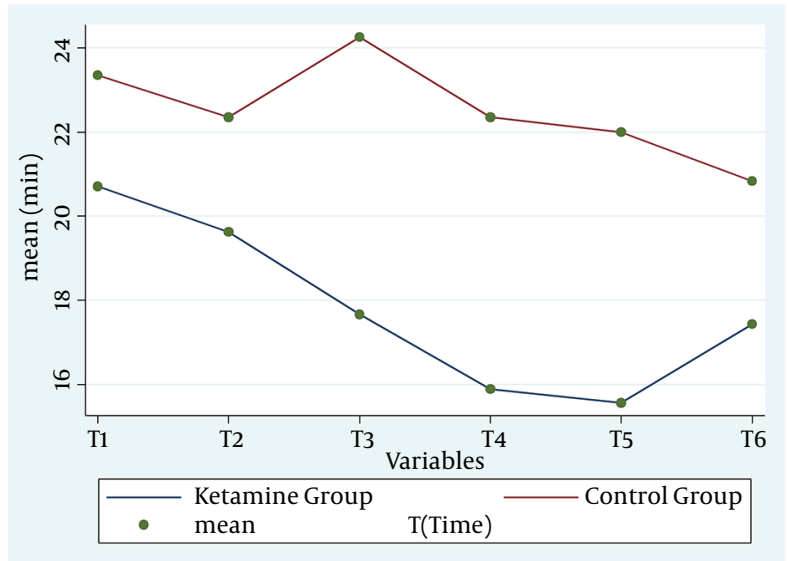

T, ECT Session.
Figure 3. Comparison of the Mean Hamilton Score Variation Between the Ketamine and Control Groups During the Treatment

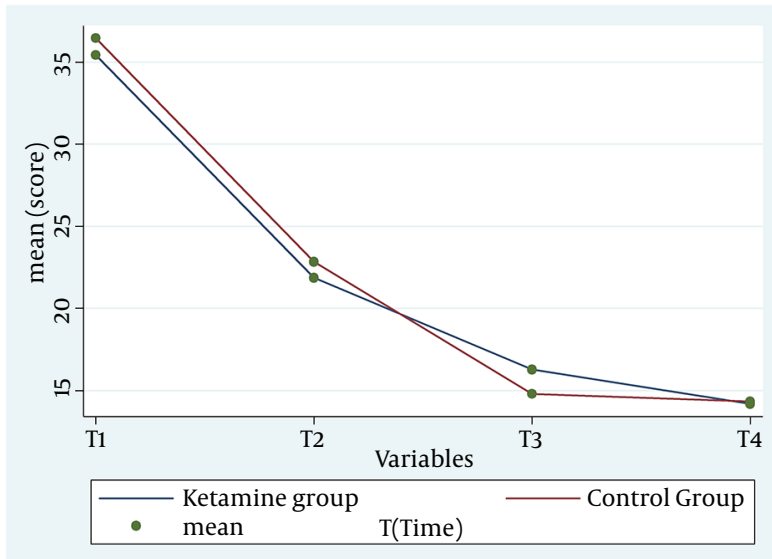

T1, one day before ECT onset; T2, A day after the third session; T3, A day after the last session; T4, Two weeks after the last session.

Iran J Psychiatry Behav Sci. 2015;9(3):e1578 


\section{Discussion}

In this study, we assessed the efficacy of Ketamine on the rate of recovery from MDD by adding it to one of the routine methods of anesthesia induction in ECT. We could not find significant differences in the symptom recovery, seizure duration, and blood pressure alterations between the two groups. However, the cognitive performance recovery time in the Ketamine group was better than in the control group.

In the current study, the evaluation of cognitive performance recovery time in both groups revealed that the patients who received Ketamine were able to answer the cognitive ability questions faster than the control group. In Mc Daniel and colleagues' study, the Ketamine-administered patients for ECT showed less memory impairment than the Etomidate-administered patients.The authors suggested the antagonistic effect of Ketamine on the NMDA receptors as a protective agent against the side effects of ECT on the cognitive abilities of patients (9). Krystal and colleagues also reported a reduction in cognitive disabilities caused by ECT after the Ketamine usage (7). In contrast, in a report by Loo and colleagues, administering Ketamine with Thiopentone did not affect the neuropsychological side effects of ECT in the treated patients. The Ketamine dose was $0.5 \mathrm{mg} / \mathrm{kg}$ in that study, and the patients underwent ultrabrief pulse-width right unilateral ECT (8). As unipolar ECT has normally fewer side effects, one of the probable reasons for the lack of efficacy of Ketamine on cognition in their study could be the different ECT modality. In addition, evidence has also shown that the Ketamine effect on glutamate transportation via the NMDA receptors is dose-dependent and is shaped like an inverted $U$ (14-16), which can be a possible explanation for the variations in different reports.

In our study, although in 5 out of 6 sessions of ECT, the motor seizure in the Ketamine-administered patients was more than that in the control patients, the difference was not significant. In both groups, the minimum seizure duration was more than 25 seconds. Our finding is in line with that reported by Kayhan and colleagues, who stated that their groups had no difference in motor seizure duration, but the quality of seizure was better in the Ketamine group. In that study, the Ketamine dose was $0.5 \mathrm{mg} / \mathrm{Kg}$ and the authors also succeeded in recording the seizure time by electroencephalography (EEG) (13). On the other hand, Krystal and colleagues showed that increasing the Ketamine dose ( 0.7 to $2.8 \mathrm{mg} / \mathrm{kg}$ ) could promote the seizure duration significantly compared with the administration of Methohexitone only (7). It seems that the difference in results stems from the Ketamine dose or mixing it with other drugs and the methods of seizure recording. As we could not record the seizures using EEG, we can make no claims regarding the quality of seizure.

The present study did not show any significant differences in terms of the cardiac side effects of Ketamine between the two groups. Although Ketamine may cause cardiac side effects due to the systemic release of catecholamines (17), the small dose of Ketamine used in this study may be the reason for the absence of cardiac side effects. It is deserving of note that some studies have shown that the combination of Ketamine and Propofol may provide better hemodynamic stability $(18,19)$.

In our study, the decreasing trend of the scores in the HRSD during the treatment for both groups showed the efficacy of both anesthesia induction methods. However, there were no significant differences in the rate and quality of recovery between the two groups $(\mathrm{P}=0.92)$. In MachadoVieira and colleagues' study, which used Ketamine as an IV single dose, the patients showed recovery in the first 24 hours (20). The rapid antidepressant effects of Ketamine were also shown in a report by Pheilps and colleagues, who studied 26 treatment-resistant patients with major depression (24). Similar effects have been reported about using Ketamine on patients with major depression and chronic pain syndrome (22), treatment-resistant patients with depression at risk of suicide (23), and also during ECT (24).

In Wang's study, the patients who received Ketamine or a Ketamine-Propofol combination during ECT experienced less depression on days 2, 3, and 7 after ECT. It is important to note that the patients in that study received only one ECT session and underwent further ECT if necessary (12).

In a study done by Goforth and colleagues, the depression symptoms of a patient were relieved 8 hours after administering $100 \mathrm{mg}$ of Ketamine and one ECT session (24). Loo showed that adding Ketamine led to better treatment efficacy in the first week but this effect had no continuity (8). It is noteworthy that there are limited studies on the combined effect of Ketamine and ECT and that they were retrospective (25) or case reports (26) or limited to one ECT session (12). Moreover, a few other similar studies did not assess the continuity of the effect $(21,22)$. Consequently, it seems that although our study could not show the effect of Ketamine on the MDD recovery in a 2-week follow-up period, the fact that there are conflicting reports on the effects of Ketamine means that such effects on depression cannot be ruled out and that they may be caused by the Ketamine dose, the onset of administering the drug before ECT, and the time of evaluating the changes in depression intensity. Therefore, more studies are recommended to reach conclusive results.

First and foremost among the limitations of the present study is that we could not record the seizure duration by EEG. Another salient drawback to this study is its small sample size due to the unavailability of patients for follow-up in Iran, which may have affected the results. Additionally, ECT discontinuation because of patient noncompliance and incomplete HRSD questionnaires because of low literacy are also the weak points of our study. Another shortcoming is the small Ketamine dose in our study by comparison with other similar studies. Indeed, achieving more reliable results requires the use of higher doses of 
Ketamine. Finally, some degree of misinterpretation by our patients in answering the HRSD questionnaire may be a possible source of bias in this study.

\section{Acknowledgements}

The authors thank the following people for their contribution to the implementation of this study: Daem Roshani, Reza Ahamdi, and the ECT Ward's nursing staff of Qods Hospital, Sanandaj.

\section{Authors' Contributions}

Narges Shams Alizadeh: substantial contributions to conception and design, drafting the article, and final approval; Azad Maroufi: substantial contributions to conception and design, drafting the article, and final approval; Karim Nasseri: substantial contributions to conception and design, critical revision for important intellectual content, and final approval; Seyed Hosein Sadeghi Najafabadi: acquisition of data, critical revision for important intellectual content, and final approval; Ali Mousavi Taghiabad: acquisition of data, critical revision for important intellectual content, and final approval; Fardin Gharibi: analysis and interpretation of data, critical revision for important intellectual content, and final approval; and Gholam Reza Esfandiari: substantial contributions to conception and design, critical revision for important intellectual content, and final approval.

\section{Conflict of Interest}

None declared.

\section{Clinical Trial Registration}

Unique identifier: IRCT1388011022935N2.

\section{References}

1. Bosker FJ, Westerink BH, Cremers TI, Gerrits M, van der Hart MG, Kuipers SD, et al. Future antidepressants: what is in the pipeline and what is missing? CNS Drugs. 2004;18(11):705-32.

2. Pagnin D, de Queiroz V, Pini S, Cassano GB. Efficacy of ECT in depression: a meta-analytic review. JECT. 2004;20(1):13-20.

3. Souery D, Papakostas GI, Trivedi MH. Treatment-resistant depression. JClin Psychiatry. 2006;67 Suppl 6:16-22.

4. Berman RM, Cappiello A, Anand A, Oren DA, Heninger GR, Charney DS, et al. Antidepressant effects of ketamine in depressed patients. Biol Psychiatry. 2000;47(4):351-4.

5. Zarate CJ, Singh JB, Carlson PJ, Brutsche NE, Ameli R, Luckenbaugh DA, et al. A randomized trial of an N-methyl-D-aspartate antagonist in treatment-resistant major depression. Arch Gen Psychiatry. 2006;63(8):856-64.

6. Liebrenz M, Borgeat A, Leisinger R, Stohler R. Intravenous ketamine therapy in a patient with a treatment-resistant major depression. Swiss Med Wkly. 2007;137(15-16):234-6.

7. Krystal AD, Weiner RD, Dean MD, Lindahl VH, Tramontozzi L3,
Falcone G, et al. Comparison of seizure duration, ictal EEG, and cognitive effects of ketamine and methohexital anesthesia with ECT. J Neuropsychiatry Clin Neurosci. 2003;15(1):27-34.

8. Loo C, Sainsbury K, Martin D, MacPherson R. Synergistic Antidepressant Effects with Ketamine and ECT. JECT. 2009;25(2):150.

9. McDaniel WW, Sahota AK, Vyas BV, Laguerta N, Hategan L, Oswald J. Ketamine appears associated with better word recall than etomidate after a course of 6 electroconvulsive therapies. J ECT. 2006;22(2):103-6.

10. Morgan CJ, Curran HV. Acute and chronic effects of ketamine upon human memory: a review. Psychopharmacology (Berl). 2006;188(4):408-24.

11. Sobin C, Sackeim HA, Prudic J, Devanand DP, Moody BJ, McElhiney MC. Predictors of retrograde amnesia following ECT. Am JPsychiatry. 1995;152(7):995-1001.

12. Wang X, Chen Y, Zhou X, Liu F, Zhang T, Zhang C. Effects of propofol and ketamine as combined anesthesia for electroconvulsive therapy in patients with depressive disorder. $J$ ECT. 2012;28(2):128-32.

13. Erdogan Kayhan G, Yucel A, Colak YZ, Ozgul U, Yologlu S, Karlidag R, et al. Ketofol (mixture of ketamine and propofol) administration in electroconvulsive therapy. Anaesth Intensive Care. 2012;40(2):305-10.

14. Li N, Lee B, Liu RJ, Banasr M, Dwyer JM, Iwata M, et al. mTOR-dependent synapse formation underlies the rapid antidepressan effects of NMDA antagonists. Science. 2010;329(5994):959-64.

15. Autry AE, Adachi M, Nosyreva E, Na ES, Los MF, Cheng PF, et al NMDA receptor blockade at rest triggers rapid behavioural antidepressant responses. Nature. 2011;475(7354):91-5.

16. Moghaddam B, Adams B, Verma A, Daly D. Activation of glutamatergic neurotransmission by ketamine: a novel step in the pathway from NMDA receptor blockade to dopaminergic and cognitive disruptions associated with the prefrontal cortex. J Neurosci. 1997;17(8):2921-7.

17. Timm C, Linstedt U, Weiss T, Zenz M, Maier C. [Sympathomimetic effects of low-dose $\mathrm{S}(+)$-ketamine. Effect of propofol dosage]. Anaesthesist. 2008;57(4):338-46

18. Rapeport DA, Martyr JW, Wang LP. The use of "ketofol" (ketaminepropofol admixture) infusion in conjunction with regional an aesthesia. Anaesth Intensive Care. 2009;37(1):121-3.

19. Andolfatto G, Willman E. A prospective case series of singlesyringe ketamine-propofol (Ketofol) for emergency departmen procedural sedation and analgesia in adults. Acad Emerg Med. 2011;18(3):237-45

20. Machado-Vieira R, Salvadore G, Diazgranados N, Zarate CI. Ketamine and the next generation of antidepressants with a rapid onset of action. Pharmacol Ther. 2009;123(2):143-50.

21. Phelps LE, Brutsche N, Moral JR, Luckenbaugh DA, Manji HK, Zarate $\mathrm{CJ}$. Family history of alcohol dependence and initial antidepressant response to an N-methyl-D-aspartate antagonist. Biol Psychiatry. 2009;65(2):181-4.

22. Correll GE, Futter GE. Two case studies of patients with major depressive disorder given low-dose (subanesthetic) ketamine infusions. Pain Med. 2006;7(1):92-5.

23. Price RB, Nock MK, Charney DS, Mathew SJ. Effects of intravenous ketamine on explicit and implicit measures of suicidality in treatment-resistant depression. Biol Psychiatry. 2009;66(5):522-6.

24. Goforth HW, Holsinger T. Rapid relief of severe major depressive disorder by use of preoperative ketamine and electroconvulsive therapy.J ECT. 2007;23(1):23-5.

25. Kranaster L, Kammerer-Ciernioch J, Hoyer C, Sartorius A. Clinically favourable effects of ketamine as an anaesthetic for electroconvulsive therapy: a retrospective study. Eur Arch Psychiatry Clin Neurosci. 2011;261(8):575-82.

26. Ostroff R, Gonzales M, Sanacora G. Antidepressant effect of ketamine during ECT. Am J Psychiatry. 2005;162(7):1385-6. 